\title{
An in-depth look at Chinese alternative food networks
}

Review by Anthony M. Fuller, University of Guelph*

Review of Organic Food and Farming in China: Top-Down and Bottom-up Ecological Initiatives, by Steffanie Scott, Zhenzhong Si, Theresa Schumilas, and Aijuan Chen. (2018). Earthscan Food and Agriculture, Routledge, London and New York. Available in hardcover and ebook; 236 pages. Publisher's website: https://www.routledge.com/Organic-Food-and-Farming-in-ChinaTop-down-and-Bottom-up-Ecological-Initiatives/Scott-SiSchumilas-Chen/p/book/9781138573000

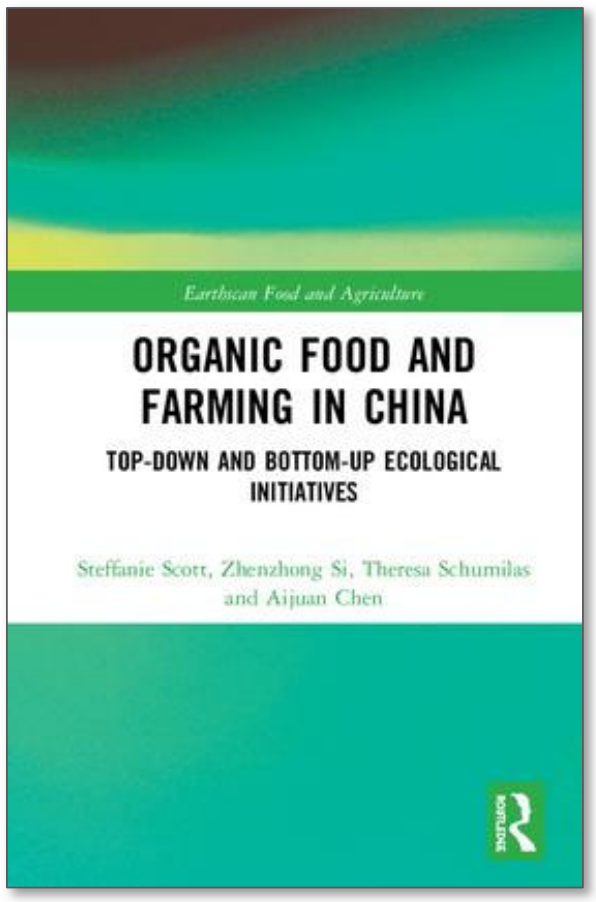

Submitted January 28, 2020 / Published online April 8, 2020

Citation: Fuller, A. M. (2020). An in-depth look at Chinese alternative food networks [Book review]. Journal of Agriculture, Food Systems, and Community Development, 9(3), 321-323. https://doi.org/10.5304/jafscd.2020.093.008

Copyright (C) 2020 by the Author. Published by the Lyson Center for Civic Agriculture and Food Systems. Open access under CC-BY license.

$T$ his book is an important contribution to our knowledge and understanding of rural China in a time of economic slowdowns, continued urbanization, and growing political unease in China. In this light, a focus on food and farming, particularly the organic sector, is welcome as it shrinks the

\footnotetext{
* Dr. Anthony M. Fuller spent 35 years teaching and researching in applied rural development in Canada and Europe. He is the author of over 70 reviewed publications and is a long-standing member of the editorial board of the Journal of Rural Studies. Since retirement, he has spent 11 years in China as senior visiting professor at the Geography and Natural Resources Division of the China Academy of Sciences and as adjunct professor at the China Agricultural University, Beijing. He can be reached at tfuller@uoguelph.ca.
}

big picture into one of its constituent parts, which permits for a more digestible view of the nature, potential, and limitations of China's alternative food sector.

The book is mainly about alternative food networks (AFNs) and, in particular, the community supported agriculture (CSA) form of networking between farmers and urban consumers. The connection between the two is much closer than in the industrial food system, where the environmental and health costs of the long food chain (multiple stages of processing and transportation) make the industrial food system potentially unsustainable. For the Chinese state, once the food security issue had been solved, the main perceived asset of the 
industrial food system is that of labor absorption and profits-not the quality, accessibility, and safety of food. This quibble and others are nicely dealt with in Chapter 2, which describes the agricultural transitions in China from the time of Opening Up in 1980 to the present, which basically produced the Chinese version of an industrial food system and a benign attitude toward the organic food sector.

Critiquing the industrial food system, however, is not the purpose of this book. The authors provide an enlightened view of CSAs, farmers markets, and buying clubs that have arisen over the past few years, which they cover in abundant if scattered detail. It is in fact one of the purposes of the book to answer why AFNs have grown so rapidly, and in response to what causes and stimuli. Here, useful comparisons are made with European and North American motivations for AFNs that do not matter in China in the same way. Instead, the overriding motive driving the growth of AFNs in China is food safety, which is a result of the many serious food scandals over the last several years. The many case studies referred to in the book demonstrate that although food freshness, environmental sustainability, and direct marketing are appreciated by consumers, it is food safety that overrides most other issues and benefits. It is important to recognize that in the main, AFNs are not an intellectual protest by consumers against the homogenizing forces of the industrial food system, but a more personal effort to avoid the health risks and doubts about processed foods.

Although the book is rich in content, being packed with facts and figures, legislative acts, pictures and case studies, sometimes it is not easy to know where to find information and explanations on specific aspects of China's many food subsystems. Composting, for example, is not allocated a mention in the index and is hard to trace in the text, despite its importance in the concept and practice of organic farming. What is covered comprehensively, however, is why many organic producers eschew certification. Avoidance of association with doubtful practices and institutions that are expensive and of questionable benefit to smallholders is well documented in several areas of the book. How the ecological farming movement began with, somewhat surprisingly, early support from the central state in the 1990s is also of considerable value. Chapter 3, "State support for Ecological and Organic Agriculture in China," provides a good account of the top-down interest and intervention in the organic farm sector, and how, over time, it has been steered toward large-scale production and export markets. Most of the organic products from scale production are certified.

Each author has a chapter to themselves. The chapter on farmers cooperatives by Chen and Scott deconstructs not only the inappropriate use of the term cooperative, but how such flexible interpretations of membership roles and responsibilities, as well as relations with the State, have enabled many new organic enterprises to get started. This illustrates the business approach to organic farming rather than the ideological origins of organics more commonly found in the West. The recent Chinese cooperative movement has become a vehicle for promoting new arrangements among farmers and food business entrepreneurs to access government fiscal and technical support. The contemporary Chinese cooperative is an example of Chinese pragmatism.

The chapter "Economic, Ecological, and Interpersonal Dimensions of AFNs," by Schumilas provide an important view, in a nicely personal and descriptive manner, of the complex local circumstances in which the organic sector has developed in many parts of China. This is extended in another interesting chapter by Schumilas on community organizing in China, which reintegrates the AFN movement into the broader contexts of traditional social patterns and restrictive political issues in China.

The most well researched chapter in this book is "Farmers' Markets as Contested Spaces," by Zhenzhong Si. Although based on only one case study, the rigor and depth to which this case is exploited raise many interesting questions for future research on the topic of farmers markets. Discussion on multiple roles and perspectives, the contested nature of what (and who) the market is for, and the tensions that arise around what is 'local' are well traced and juxtaposed among the many actors.

In Chapter 9 by $\mathrm{Si}$ and Scott, an effort is made to relate AFNs to rural development in China, 
which is doomed to disappoint, because there is no 'official' rural development in China, other than several attempts at rural industrialization during and since the time of Mao. Instead, the authors trace the origins and revival of the Rural Reconstruction Movement, which was an attempt to reinstall many of the values and principles of rural communities as envisioned by a well-meaning group of urbanites. The New Rural Reconstruction Movement (NRRM) becomes the main focus of Chapter 9 and demonstrates the problems of thirdsector initiatives in contemporary China, as the connections between CSAs and NRRM are frowned upon by the state. Nevertheless, as elsewhere, and for English-only readers in particular, the tracing of the development of such movements is of considerable value, as their existence and experiences are largely unknown in the West.

This account of alternative food networks embedded in the context of contemporary rural China is of immense value in unravelling the many layers of complexity regarding food systems and the various aspects of the AFN phenomena. Much of the inference in the text is about trust: lack of con- sumer trust in the industrial food system, lack of trust between organic farmers and government, between organic farmers and eco-certification, etc., while building new forms of trust through farmers markets and CSAs. This is effective partly because many urbanites are only one generation away from the farm and easily gravitate to what is familiar and perceived as trustworthy.

It is also particularly pleasing that the style of the book is open and friendly, with many photographs of the lead author undertaking her field work. This authenticity of style softens the dominant presence of the formal state in matters of agriculture, which is dealt with in only a mildly critical way. The perspectives of the two Chinese authors helps make this volume authoritative and credible. The book is informative and easy to read. As a yardstick of contemporary alternative issues in rural China, this book is an important reference and provides scholarship with a friendly face. The group leader, Professor Steffanie Scott, is to be congratulated in coordinating a coherent account of this somewhat eclectic research field of organic food and farming in China. 